\title{
The effects onto springback of waiting time in sheet metal forming
}

\author{
Kadir Gok ${ }^{*}$ \\ Dumlupinar University, Kutahya Vocational School of Technical Sciences, Germiyan \\ Campus, 43100 Kutahya/Turkey
}

Mehmet Erdem

Dumlupinar University, Kutahya Vocational School of Technical Sciences, Germiyan Campus, 43100 Kutahya/Turkey

Mehmet Ali Alkan

Department of Electricity and Energy, Ula Ali Koçman Vocational High School, Muğla Sitkı Koçman University, 48640 Ula, Muğla, Turkey

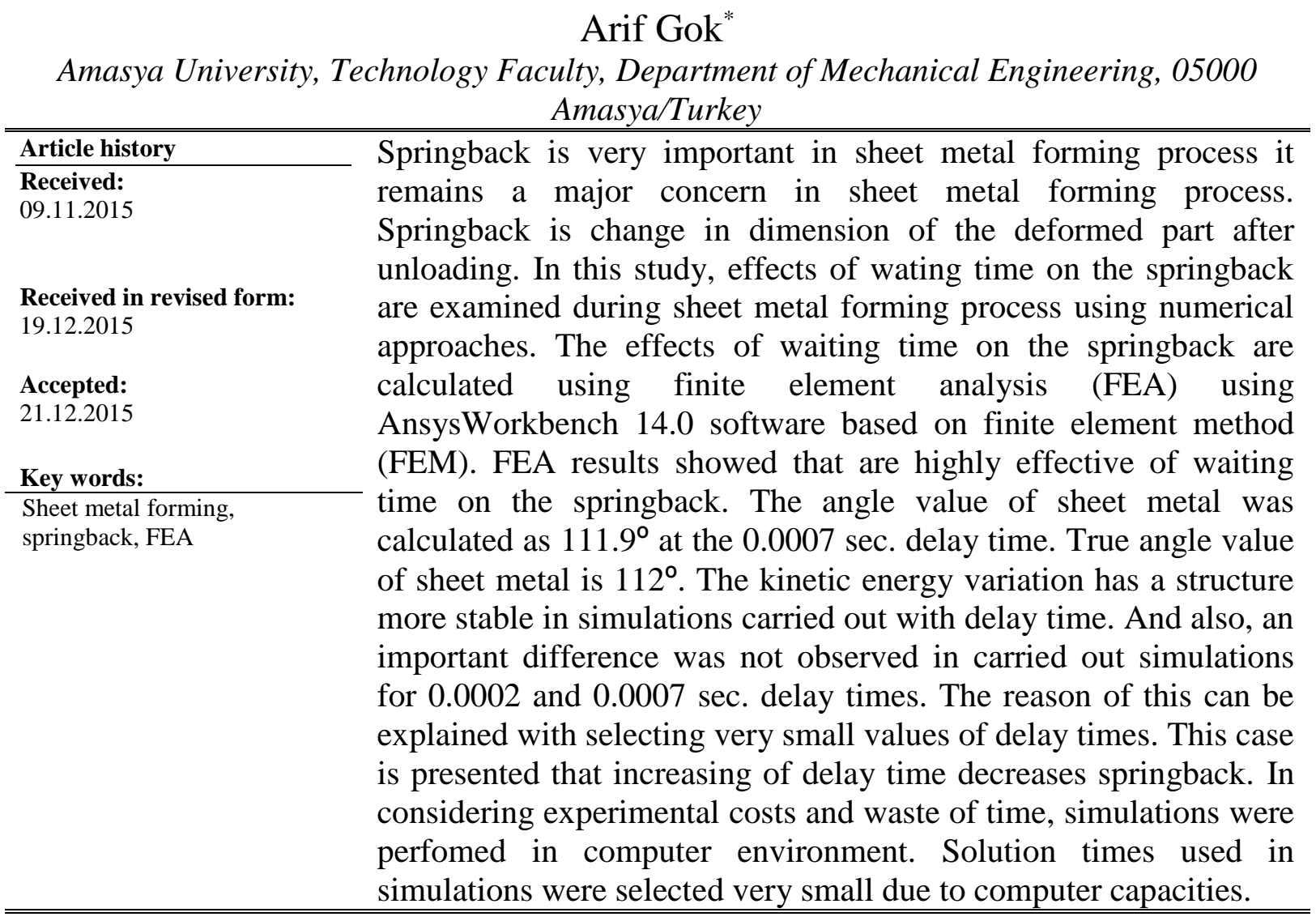

Correspondence: arif.gok@amasya.edu.tr 


\section{Introduction}

Metal forming has a large group of manufacturing processes and it is used to change the shape of metal workpieces. The metal workpieces with metal forming is plastically deformed. In general, metal forming processes can be divided as two groups. These processes are bulk deformation and sheet metal forming. Bulk deformation processes are generally performed significant deformations and massive shape changes, while sheet metal forming processes are formed on metal sheets and strips. In order to deform a sheet metal, punch, die and sheet are used in as seen in Fig. 1. Sheet metal forming processes involve a few operations such as cutting, drawing and bending. As seen in Figure, die and pot ring are fixed by fasteners in $\mathrm{x}, \mathrm{y}$ and $\mathrm{z}$ axes, while punch is fixed in $\mathrm{x}$ and $\mathrm{y}$ axes, but it is free in $\mathrm{z}$ axis. The sheet metal is between punch and die. The punch is acting in $\mathrm{Z}$ axis, and it deforms the sheet metal. Deformation result in stresses that exceed the yield strength of the sheet metal. The metal therefore deforms to take a shape determined by the geometry of the die [1].
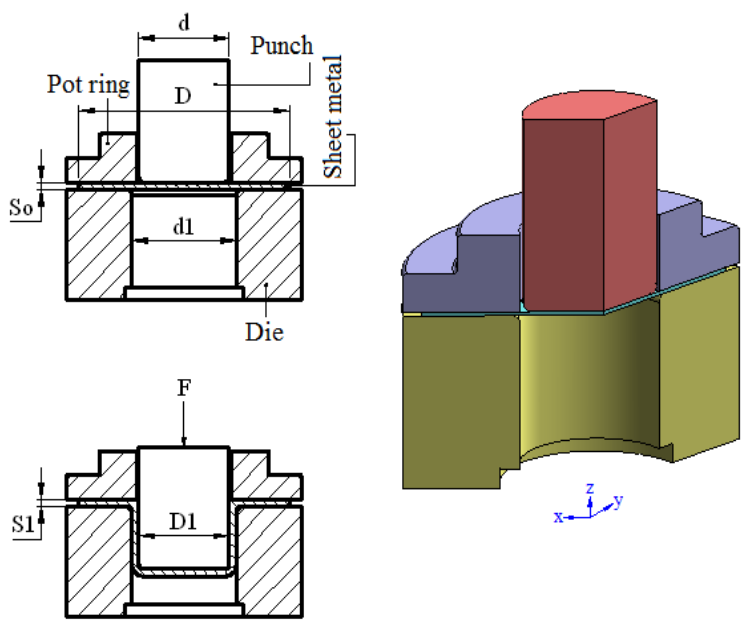

Fig. 1: Deep drawing process

Bending is such a shaping process used commonly in various sheet metal industrial products. To understand how this process is so common, it is enough to have a look at automobiles and housing utensils, etc.
The sheet parts in these products and in the others are shaped using bending dies. [2]. Bending in sheet metal work is defined as the straining of the metal around a straight axis, as Fig. 2a. During the bending operation, the metal on the inside of the neutral plane is compressed, while the metal on the outside of the neutral plane is streched. Bending process is also used for increasing the strength of the metal sheets. These strain conditions can be seen in Fig. $2 b$.

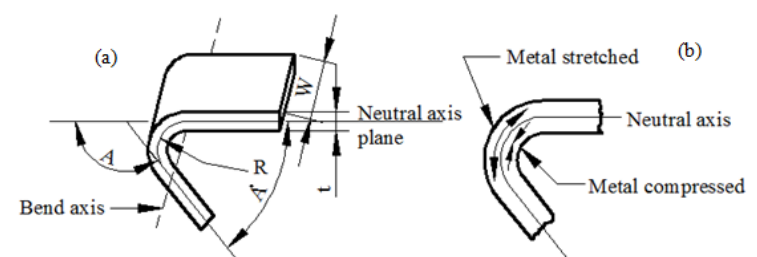

Fig. 2: Bending of sheet metal (a), both compression and tensile elongation of the metal occur in bending (b) [1]

Several researches have been studied in relation to springback in metal forming processes. Tekaslan et al. [3] This research has been conducted to determine experimentally springback of sheet metals on bending dies. The amount of springback in sheet metals at different bending angles has been obtained by designing a modular $\mathrm{V}$ bending die. Yuan [4] tried to lessen springback, in the material subjected to plastic deformation, through redistribution of elastic stresses inside the material after the release of the affecting load. Up to now, springback has been limited to homogenous materials. Upon the increase in the use of composite materials in engineering, Yuan looked for and presented a mathematical model solution to determine springback for such materials. A new mathematical method is prepared by Zhang et al. [5] for the analysis of springback in metal sheet forming. The model is used to determine the springback and bending moment force. Tekiner [2], an experimental study has been carried out on the determination of springback of bent products. Hence, the amount of springback of several sheet metals with different bending angles was obtained on a modular V-bending 
die, which was designed and constructed, and the springback graphics were plotted. Meinders et al. [6] developed an analytical model for the springback prediction, compensation, and optimization based on the through-thickness integration scheme for shell elements. In addition to these Ling et al. [7] in order to reduce time spent on such manual corrections of the die, a parametric study is conducted on how the inclusion of a step in the die may reduce springback in Lbending of sheet metal. Panthi et al. [8] carried out to observe the influence of geometric parameters on the springback using FEA. Teti and Costa [9] carried out to verify the stamping process and the shape of the final component for studying springback of AHSS with numerical simulation.

The springback is unwanted situation in sheet metal molding. If springback occurs after forming process, this sheet metal is not sensitively placement to assembly environment. There are available many methods about prevent of springback. The methods such as increasing of mold radius and angle, change of mold clearance are effective on the springback. In addtion to these methods, delay time at the stroke end is one of the most important methods for springback. The purpose of this study is to investigate the effects of wating time on the springback occured during sheet metal forming process using FEA. The springback values were also calculated using FEA with AnsysWorkbench 14.0 software.

\section{Computer Aided Finite Element Analysis}

A commercial finite element based program, AnsysWorkbench, is employed to predict effects of waiting time on the springback. The modeling of the punch, die and sheet are performed in 3D using SolidWorks 2013 program. These models are imported into AnsysWorkbench to prepare the finite element model.

\section{Loading and Boundary Conditions}

The 3D models are imported into AnsysWorkbench workbench and the mesh generation of the FEA is created. The mesh generation of the models is created using hexagonal element type as seen in Fig. 3. The die is fixed from clamped faces to vice. Contact definitions among the parts (punch, die and sheet) are defined as a frictional contact. Additionally, frictional contact is defined between the punch-sheet and diesheet. These friction coefficients are 0.3 for static friction and 0.25 for dynamic friction, respectively. The generated finite element model has 239955 nodes and 220950 elements. While the punch and die parts were selected as rigid material, sheet metal part was selected as steel. Cowper-Symonds material model was selected for simulations.

$\sigma_{0}$ is initial yield strength, $\mathrm{C}$ and $\mathrm{P}$ are Cowper-Symonds strain rate, $\varepsilon_{p}^{e f f}$ is effective plastic strain, $\dot{\varepsilon}$ is strain rate and $E_{p}$ is plastic hardening modulus. The mechanical properties of sheet metal were given in Table 1.
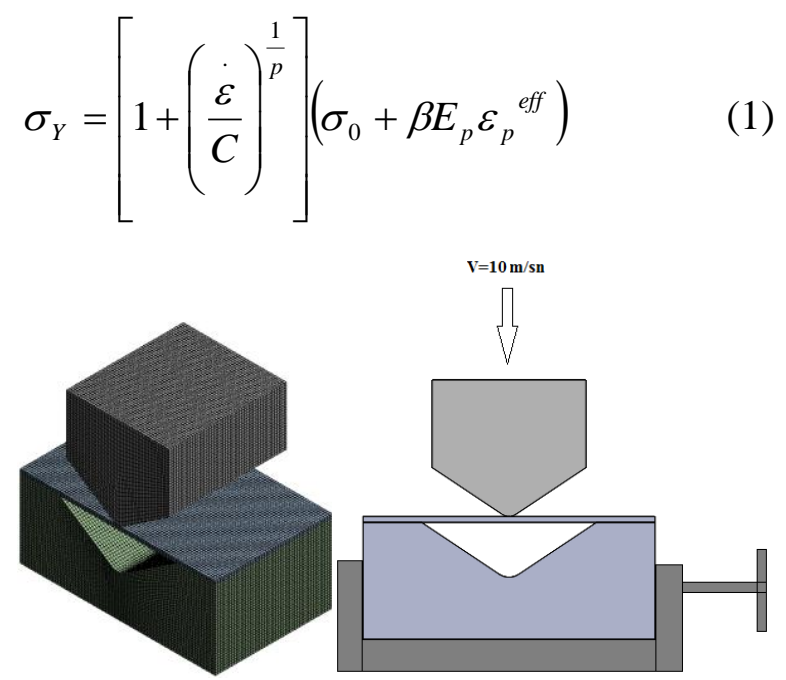

Fig. 3: Mesh model and boundary conditions 
Tablo 1 The mechanical properties of sheet (Structural steel) [10]

\begin{tabular}{|l|l|}
\hline Mechanical Properties & Structural Steel \\
\hline Elasticity Module $(\mathrm{Pa})$ & $200 \times 109$ \\
\hline Density $(\mathrm{kg} / \mathrm{m} 3)$ & 7865 \\
\hline Poisson's Ratio & 0.27 \\
\hline Yileding Strength $(\mathrm{Pa})$ & $310 \times 106$ \\
\hline Tangential Module $(\mathrm{Pa})$ & $763 \times 106$ \\
\hline $\mathrm{C}(\mathrm{Cs}-1)$ & 40 \\
\hline $\mathrm{P}$ & 5 \\
\hline$\varepsilon p$ & 0.75 \\
\hline
\end{tabular}

\section{Results and Discussion}

It was observed to be very effective of delay time in $\mathrm{V}$-bending process from sheet metal forming. Especially, increasing of delay time decreases springback value as seen in Figure 3. The angle value of sheet metal was calculated as $111.9^{\circ}$ at the 0.0007 sec. delay time. True angle value of sheet metal is $112^{\circ}$. This case is presented that increasing of delay time decreases springback. Kinetic energy variation $\mathrm{s}$ in sheet metals at the different delay times were calculated and presented grafically in Figure 4. As seen in this figure, while kinetic energy is subject to too much change for simulations carried out without delay time (0 sec.). The kinetic energy variation has a structure more stable in simulations carried out with delay time. And also, an important difference was not observed in carried out simulations for 0.0002 and 0.0007 sec. delay times. The reason of this can be explained with selecting very small values of delay times. When these values are selected higher, it is expected to be more significant of this difference.
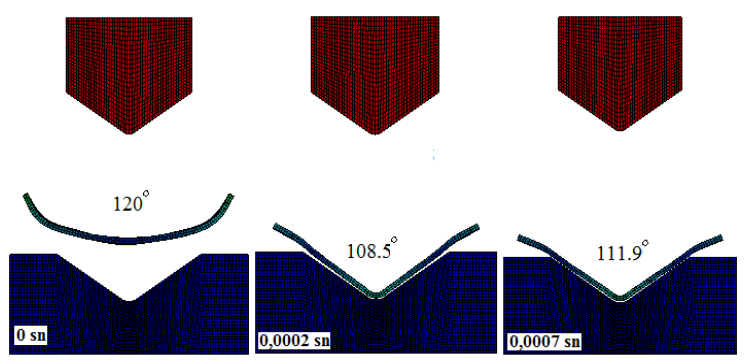

Fig. 3: Simulation processes at different delay times

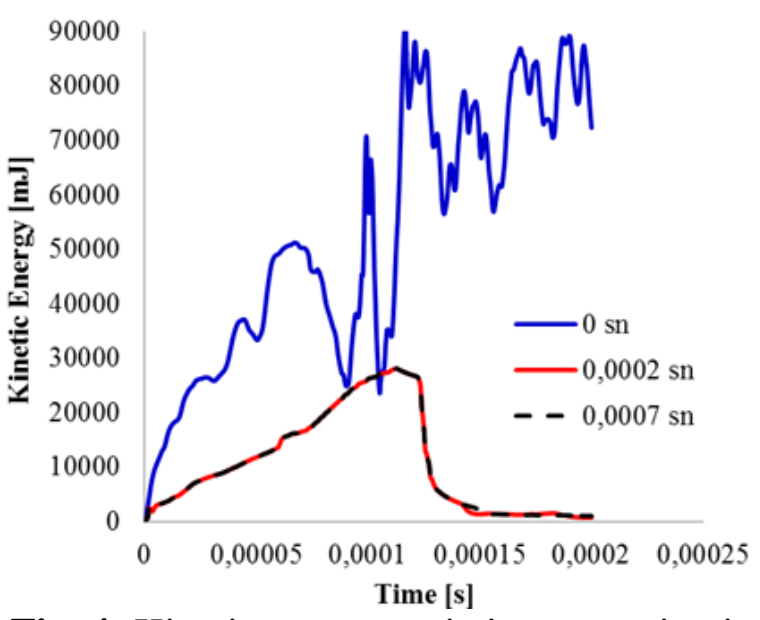

Fig. 4: Kinetic energy variations occuring in sheet metals at the different delay times

\section{Conclusion}

This study was performed to find an alternative solution the commonly encountered springback value in metal forming processes. It was observed to be very effective on the springback of delay time. In considering experimental costs and waste of time, simulations were perfomed in computer environment. Solution times used in simulations were selected very small due to computer capacities. These solution times can be selected times higher using a more powerful workstations.

\section{References}

[1] Groover MP, "Fundamentals of Modern Manufacturing", Materials, Processes, and Systems, John Wiley \& Sons, 2010

[2] Tekiner Z, "An experimental study on the examination of springback of sheet metals with several thicknesses and properties in bending dies", Journal of Materials

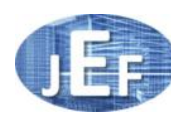


Processing Technology, 145 (1):109-117, 2004

[3] Tekaslan Ö, Gerger N, Şeker U, "Determination of spring-back of stainless steel sheet metal in "V" bending dies", Materials \& Design, 29(5):1043-1050, 2008

[4] Yuen WYD, "A generalised solution for the prediction of springback in laminated strip", Journal of Materials Processing Technology,61(3):254-264, 1996

[5] ZHANG ZT, LEE D, "Development of a new model for plane strain bending and springback analysis", JMEP, 4 (3):291300, 1995

[6] Meinders T, Burchitz IA, Bonte Mha, Lingbeek RA, "Numerical product design: Springback prediction, compensation and optimization", International Journal of
Machine Tools and Manufacture, 48:499514, 2007

[7]. Ling Ye, Lee HP, Cheok BT, "Finite element analysis of springback in Lbending of sheet metal", Journal of Materials Processing Technology, 168 (2):296-302, 2005

[8] Panthi SK, Ramakrishnan N, Ahmed M, Singh SS, Goel MD, "Finite Element Analysis of sheet metal bending process to predict the springback", Materials \& Design, 31 (2):657-662, 2010

[9] Teti R, Costa J, "Springback prediction with FEM analysis of advanced high strength steel stamping process", 2010

[10] AnsysWorkbench Material Library. 